\title{
Current understanding of iberiotoxin-resistant BK channels in the nervous system
}

\author{
Bin Wang ${ }^{1}$, David B. Jaffe ${ }^{2}$ and Robert Brenner ${ }^{1 *}$ \\ ${ }^{1}$ Department of Physiology, University of Texas Health Science Center at San Antonio, San Antonio, TX, USA \\ ${ }^{2}$ Department of Biology and the UTSA Neurosciences Institute, University of Texas at San Antonio, San Antonio, TX, USA
}

\section{Edited by:}

Thomas M. Weiger, University of

Salzburg, Austria

Reviewed by:

Neil V. Marrion, University of

Bristol, UK

Alexi Alekov, Medizinische

Hochschule Hannover, Germany

*Correspondence:

Robert Brenner, Department of Physiology, University of Texas Health Science Center at San Antonio, 7703 Floyd Curl Drive, San Antonio, TX 78229, USA

e-mail:brennerr@uthscsa.edu
While most large-conductance, calcium-, and voltage-activated potassium channels (BK or Maxi-K type) are blocked by the scorpion venom iberiotoxin, the so-called "type II" subtype has the property of toxin resistance. This property is uniquely mediated by channel assembly with one member of the BK accessory $\beta$ subunit family, the neuron-enriched $\beta 4$ subunit. This review will focus on current understanding of iberiotoxin-resistant, $\beta 4-c o n t a i n i n g$ BK channel properties and their function in the CNS. Studies have shown that $\beta 4$ dramatically promotes BK channel opening by shifting voltage sensor activation to more negative voltage ranges, but also slows activation to timescales that theoretically preclude BK ability to shape action potentials (APs). In addition, $\beta 4$ membrane trafficking is regulated through an endoplasmic retention signal and palmitoylation. More recently, the challenge has been to understand the functional role of the iberiotoxin-resistant BK subtype utilizing computational modeling of neurons and neurophysiological approaches. Utilizing iberiotoxin-resistance as a footprint for these channels, they have been identified in dentate gyrus granule neurons and in purkinje neurons of the cerebellum. In these neurons, the role of these channels is largely consistent with slow-gated channels that reduce excitability either through an interspike conductance, such as in purkinje neurons, or by replacing fast-gating BK channels that otherwise facilitate high frequency AP firing, such as in dentate gyrus neurons. They are also observed in presynaptic mossy fiber terminals of the dentate gyrus and posterior pituitary terminals. More recent studies suggest that $\beta 4$ subunits may also be expressed in some neurons lacking iberiotoxin-resistant BK channels, such as in CA3 hippocampus neurons. Ongoing research using novel, specific blockers and agonists of $B K / \beta 4$, and $\beta 4$ knockout mice, will continue to move the field forward in understanding the function of these channels.

Keywords: BK channel, iberiotoxin, beta4, KCNMB4, type II bk channels, KCNMA1, MaxiK, calcium-activated potassium channel

\section{INTRODUCTION}

While $\mathrm{BK} \mathrm{K}^{+}$channels are often identified using the scorpion venom iberiotoxin, seminal work by Rinehart and Levitan identified an iberiotoxin-resistant, slow-gated BK channel subtype from brain synaptosomal membranes (Reinhart et al., 1989; Reinhart and Levitan, 1995). The investigators classified this as the socalled "type II BK channel" which was in contrast to the more conventional iberiotoxin-sensitive type I, fast-gated BK channels. A similar type II toxin-resistant BK channel was observed in posterior pituitary nerve terminals soon after (Bielefeldt et al., 1992; Wang et al., 1992). The molecular basis for type II BK channels was revealed in 1999 when random cDNA sequences began flooding DNA databases and perusing BKologists identified three additional accessory subunit family members $(\beta 2, \beta 3$, and $\beta 4)$ similar to the previously cloned $\beta 1$ that modulate the BK poreforming $\alpha$ subunit. Among these, the neuron-specific $\beta 4$ subunit was found to confer the slow-gating and iberiotoxin-resistance that likely underlies the type II BK channels seen in synaptosomal membranes (Behrens et al., 2000; Brenner et al., 2000; Meera et al., 2000; Weiger et al., 2000; Lippiat et al., 2003). This was confirmed by gene knockout of the $\beta 4$ subunit that converted BK channels in neurons from iberiotoxin-resistant to iberiotoxinsensitive channels (Brenner et al., 2005). While cloned more than 14 years ago, our understanding of the functional role of $\beta 4$ containing $B K$ potassium channels in neurons is still very limited. This short review will discuss current understanding of $B K / \beta 4$ biophysical properties, their regulation, and neurophysiological function.

\section{BK CHANNELS ARE COMPOSED OF DIVERSE SUBTYPES IN CENTRAL NEURONS}

Large conductance calcium-activated (BK-type) potassium channels are potassium channels uniquely activated by both calcium and depolarization (Kaczorowski et al., 1996; Gribkoff et al., 1997; Calderone, 2002). When open, BK channels have among the largest ion channel conductance $(>200 \mathrm{pS})$ and are very effective in hyperpolarizing the membrane. BK channels are expressed relatively broadly in many excitatory neurons of the 
CNS (Wanner et al., 1999). Early studies used scorpion venoms including charybdotoxin, and later the uniquely BK-selective iberiotoxin, to block channels and thereby study BK effects in neurons. Use of these blockers has revealed their key role in shaping action potentials. Depending on the neuron, BK channels affect the repolarization phase and the fast-component of the afterhyperpolarization to various extents (Sah and Faber, 2002).

Although the pore-forming subunit ( $\alpha$ subunit) is encoded by a single gene, a family of four tissue-specific accessory subunits, $\beta 1$ through $\beta 4$ (Orio et al., 2002), confer BK channels with diverse functional properties affecting steady-state conductance properties, gating kinetics, inactivation, and pharmacology (Behrens et al., 2000; Brenner et al., 2000). Expression studies suggest that $\beta 2$ and $\beta 4$ are the principle $\beta$ subunits expressed in central neurons (Figure 1A) (Brenner et al., 2000), and electrophysiology and pharmacology studies (discussed below) suggest that $\alpha$ interactions with these subunits define one of three BK channel subtypes generally observed in central neurons. These are the inactivating $\mathrm{BK}$ channels $(\alpha+\beta 2)$, and the non-inactivating type I ( $\alpha$ alone) and type II BK channels $(\alpha+\beta 4)$. A simple overview of some key properties that distinguishes these channel subtypes in neurons is shown in Figure 1B. In heterologous expression systems, the accessory $\beta 2$ subunit confers $\mathrm{N}$-type inactivation to $\mathrm{BK}$ channels and is sensitive to iberiotoxin block (Wallner et al., 1999; Xia et al., 1999). Inactivating BK channels are observed in CA1 (Cornu Ammonis-1) neurons of the hippocampus (McLarnon, 1995) and adrenal chromaffin cells (Solaro and Lingle, 1992). The effect of these channels in central neurons is to repolarize the first few, but not later, action potentials in a train, resulting in a frequency-dependent spike broadening (Shao et al., 1999; Faber and Sah, 2003). Although inactivating BK channels are likely mediated by the $\beta 2$ accessory subunit, some splice products of the $\beta 3$ subunit also confer inactivation. However, this protein has weak expression in the brain (Wallner et al., 1999; Xia et al., 1999; Uebele et al., 2000; Hu et al., 2003).

The non-inactivating type I and type II BK channel subtypes were originally identified from bilayer recordings from synaptosomal membrane preparations from brain (Reinhart et al., 1989; Reinhart and Levitan, 1995). Type I BK channels have relatively fast gating kinetics, are sensitive to iberiotoxin block, and likely represent BK channels lacking accessory $\beta$ subunits. Type II BK channels have slow gating kinetics and are insensitive to

\section{A Neuronal, Calcium- \& Voltage-Activated (BK) Potassium Channel Subunits}

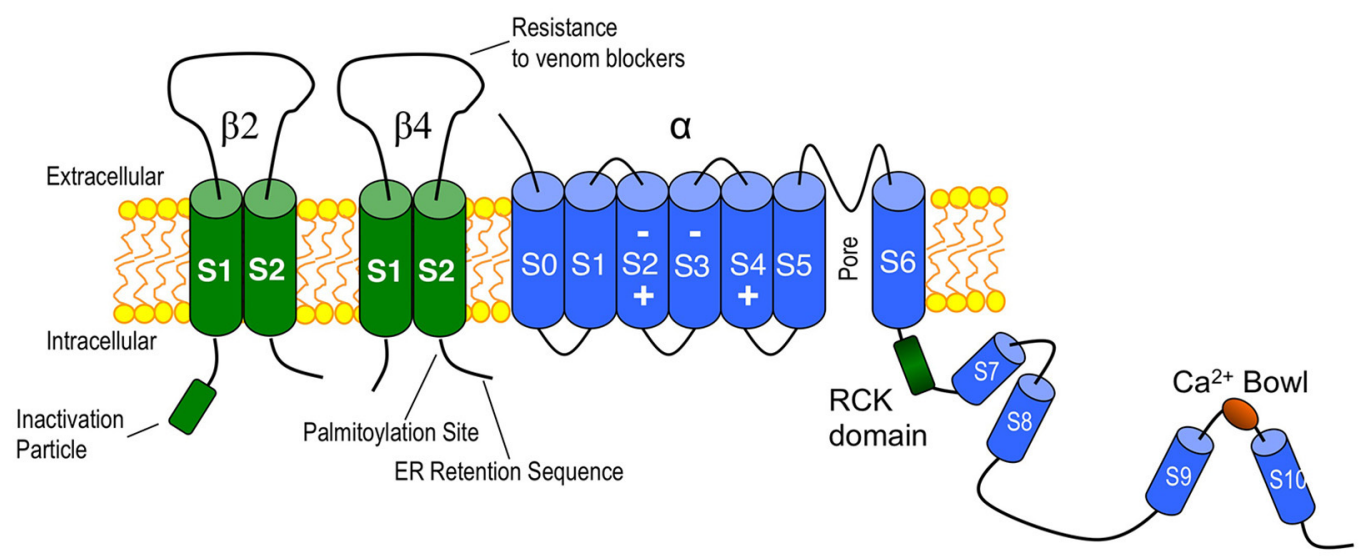

B

Neuronal BK Channels (Paxilline-sensitive)

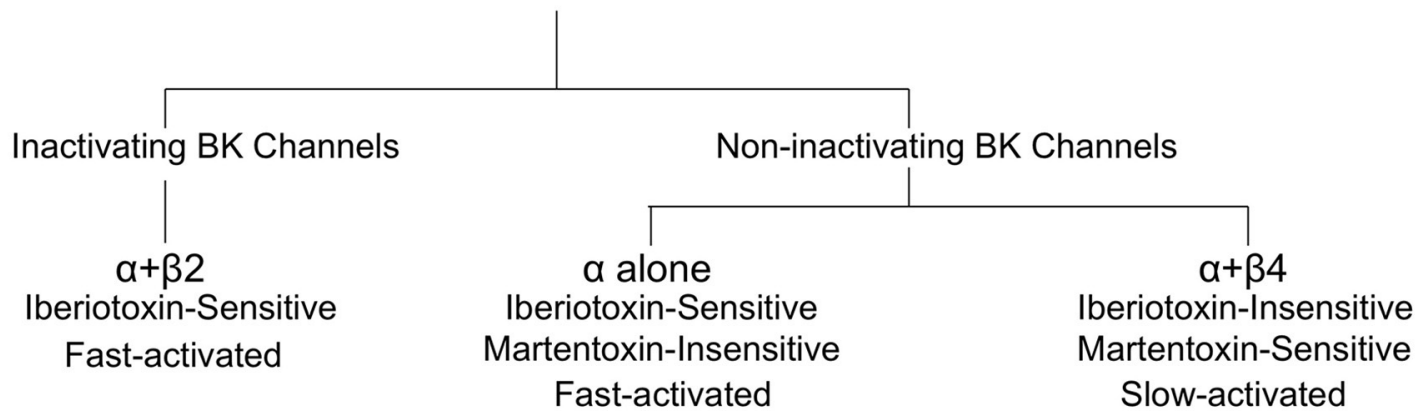

FIGURE 1 | (A) Cartoon of the major BK channel subunits expressed in neurons of the central nervous system and key domains. "Inactivation particle" is $\beta 2$ amino terminal sequence that confers fast-type inactivation on BK channels (Wallner et al., 1999; Xia et al., 1999). The $\beta 4$ subunit extracellular domain contains residues that confer BK channel "resistance to venom blockers" including charybdotoxin and iberiotoxin (Meera et al., 2000;
Gan et al., 2008). Surface trafficking of $\beta 4$ is regulated by carboxyl-terminal "palmitoylation" (Chen et al., 2013) and an "ER (endoplasmic reticulum) retention sequence" (Shruti et al., 2012; Cox et al., 2014). The BK channel is depicted with voltage-sensor regions (S2-S4) (Ma et al., 2006) and calcium binding sites (RCK and $\mathrm{Ca}^{2+}$ bowl domains) (Bao et al., 2002; Xia et al., 2002). (B) Flow chart of neuronal BK channel pharmacology and gating properties. 
iberiotoxin block (Reinhart et al., 1989). As discussed below, the slow gating and iberiotoxin-resistance are hallmarks of BK channels containing $\beta 4$ subunits. In addition, type II BK channels are coupled to protein kinase $\mathrm{C}$ and protein phosphatase (Reinhart and Levitan, 1995). Historically the functional role of type II BK channels are less understood perhaps due to their resistance to iberiotoxin block, but also because they are less often observed in neurons. Later, paxilline was identified as a useful blocker for BK channels (Knaus et al., 1994) that indiscriminately blocks both type I and type II BK channels (Hu et al., 2001). Thus, investigators can unambiguously identify BK/ $\beta 4$ channels as those that are resistant to iberiotoxin and sensitive to paxilline. Recently, Martentoxin (Shi et al., 2008; Tao et al., 2012) and Conopeptide Vt3.1 (Li et al., 2014) were identified as more selective blockers of BK/ $\beta 4$ channels than the pore-forming $\alpha$ subunit alone. The neuronal $\beta 2$ subunit does not alter Conopeptide Vt3.1 block (Li et al., 2014). Whether or not Martentoxin also blocks $\mathrm{BK} / \beta 2$ channels has not been established with certainty. Although Martentoxin blocks a large fraction of BK currents in adrenal chromaffin cells where BK/ $\beta 2$ channels are expressed (Ji et al., 2003), pharmacological studies on pure $\alpha+\beta 2$ have not yet been conducted.

\section{$\beta 4$ SUBUNITS SLOW GATING AND INCREASE OPEN PROBABILITY OF BK CHANNELS}

BK channels are unique among other potassium channels in being activated by both voltage and calcium. Therefore, these channels are believed to be a negative feedback mechanism regulating voltage-dependent calcium channels and other calcium-modulated voltage-dependent channels (Figure 2A). Theoretically, the tissue-specific accessory $\beta$ subunits tune the response properties of $\mathrm{BK}$ channels to the needs of the cell. The dual activation properties of BK channels are most clearly apparent in single channel recordings (Figure 2B). In constant calcium $(1.7 \mu \mathrm{M}$ internal calcium, Figure 2B, left panel) channel opening increases in a voltage-dependent manner. As well, at constant voltage $(+40 \mathrm{mV}$, Figure $2 \mathrm{~B}$, right panel) increasing calcium increases channel open probability. The response properties of BK channels to voltage and calcium are well represented in plots of conductance-voltage relationships ( $\mathrm{G}-\mathrm{V}$ relationships, Figure 2C). The pore-forming subunit of BK channels ( $\alpha$ subunit) binds calcium at affinities that are relatively low (tens of micromole) compared to physiological global calcium concentrations (i.e., bulk calcium rises that occur throughout the cell, 100-200 nM) (Cox et al., 1997; Cui et al., 1997). At resting calcium concentrations (nanomolar) BK channels in neurons do not show significant channel openings at physiological voltage ranges (Horrigan et al., 1999) (Figure 2C). Thus, to obtain high open probabilities, BK channels require coincident depolarization and calcium rises such as might occur during an action potential and in close apposition to voltage-activated calcium channels (Fakler and Adelman, 2008). Experimentally, the dual calcium and voltage sensitivities are seen as shifts of the $\mathrm{G}-\mathrm{V}$ relations to negative potentials with increasing calcium (Figure 2C). Thus,

\section{A}

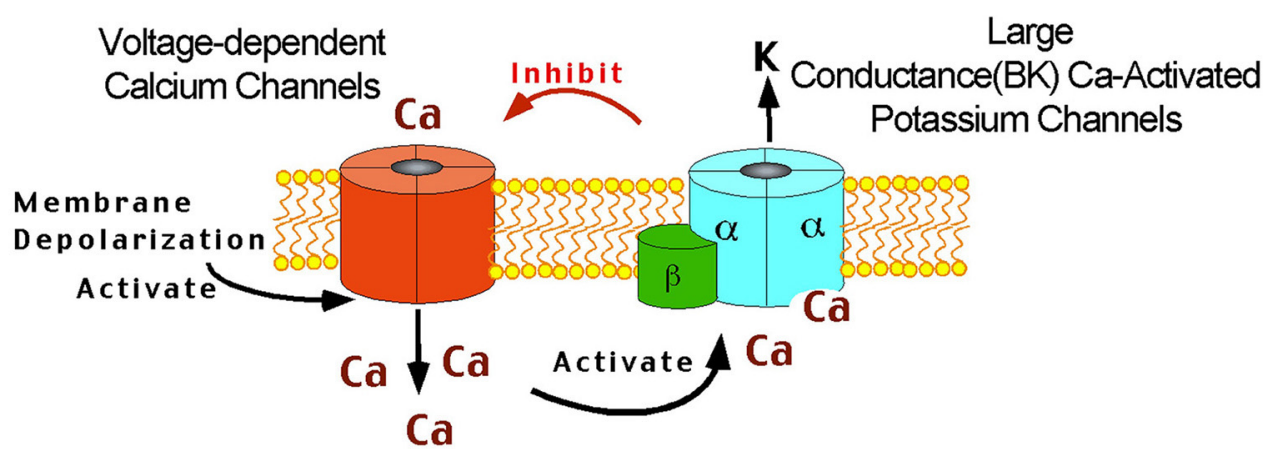

B Voltage Activation

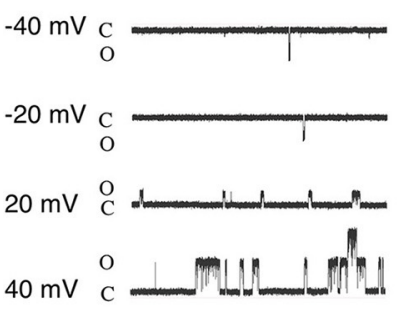

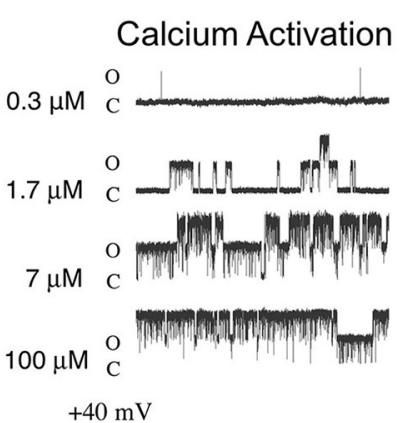

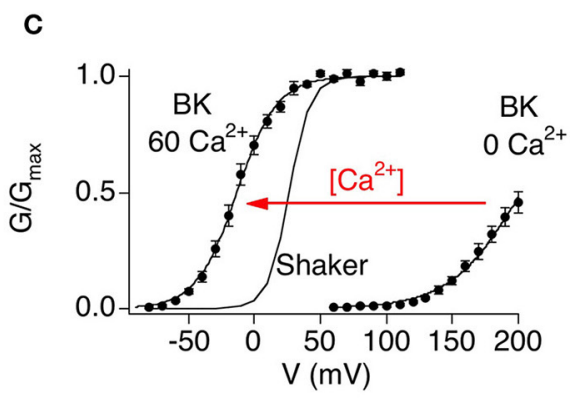

FIGURE 2 | (A) Cartoon of voltage-dependent calcium channel and BK channel negative feedback mechanism. Depolarization opens voltage-dependent calcium channels. The coincident calcium influx and depolarization activate BK channels, that in-turn, repolarize the membrane and deactivate voltage-dependent currents. (B) Single channel recording of $\mathrm{BK} \alpha$ alone at various voltage (left panel) and calcium (right panel). Note: there are two BK channels in this patch. (C) Conductance-voltage relations of BK $\alpha$ alone recorded from inside/out patches containing macroscopic currents. $0 \mathrm{Ca}^{2+}$ is internal solution containing $5 \mathrm{mM}$ EGTA to buffer calcium. $60 \mu \mathrm{M}$ internal calcium shifts the $\mathrm{G}-\mathrm{V}$ relations to more negative membrane potentials. 
neurons can theoretically convert BK channels from channels that are high voltage-activated channels, to channels activated at threshold or subthreshold potentials by dynamically increasing calcium concentrations. Indeed, although Shaker-type Kv channels are more voltage-sensitive than BK channels, high local calcium can cause BK channels to open in a voltage-dependent fashion at more negative membrane potentials (Figure 2C).

Functional studies in heterologous expression systems provided strong evidence that $\beta 4$ confers properties of type II BK channels. The extracellular domain of $\beta 4$ has been shown to occlude toxin binding to BK channels, a key property of type II channels (Meera et al., 2000; Gan et al., 2008). The $\beta 4$ subunits' predominant effect on channel gating is to slow activation and deactivation kinetics, also a property of type II channels (Behrens et al., 2000; Brenner et al., 2000; Ha et al., 2004; Wang et al., 2006). This is quite obvious in the slow activation rise time and slow tail currents, respectively (Figures 3A,B). The biophysical mechanisms underlying kinetic changes are not understood. $\beta 4$ also modulates steady-state properties by causing negative shifts of the conductance-voltage relations in high calcium $(>\sim 10 \mu \mathrm{M})$ but positive shifts in low calcium (Behrens et al., 2000; Brenner et al., 2000; Lippiat et al., 2003; Ha et al., 2004; Wang et al., 2006). These effects on channel opening suggest that $\beta 4$ regulates BK channels through multiple, opposing mechanisms on channel opening. Several studies have investigated how $\beta 4$ alters steady-state gating (Wang et al., 2006; Contreras et al., 2012) in the context of an allosteric gating model for BK channels (Horrigan and Aldrich, 1999; Horrigan et al., 1999; Rothberg and Magleby, 1999). The allosteric model describes BK channel opening to be due to relatively independent coupling of voltage-sensors and $\mathrm{Ca}^{2+}$ sensors to the channel gate [(Horrigan and Aldrich, 2002); an excellent, short review in Lingle (2002)]. $\beta 4$ was shown to increase BK channel opening by shifting voltage-sensor activation to more negative potentials (Wang et al., 2006; Contreras et al., 2012). This property has also been reported for the related $\beta 1$ and $\beta 2$ subunits (Bao and Cox, 2005; Orio and Latorre, 2005; Contreras et al., 2012). Channel modeling studies of $\beta 4$ effects suggest that this calcium-independent property contributes to the negativeshift of the conductance-voltage relations that is apparent at high calcium (Wang et al., 2006). How does $\beta 4$ reduce channel opening (cause a positive-shift of the conductance-voltage relations) at low calcium? Two mechanisms have been ascribed to this effect. $\beta 4$, like the related $\beta 1$ and $\beta 2$, cause an increased energetic barrier for gate opening (Orio and Latorre, 2005; Wang and Brenner, 2006; Wang et al., 2006). As well, $\beta 4$ was shown to reduce gating charge which also can contribute to reduced channel openings (Contreras et al., 2012).

The slow gating and the depolarization of the $\mathrm{G}-\mathrm{V}$ relations at low calcium suggested that $\beta 4$ subunits could be regarded as an inhibitory neuronal subunit of BK channels (Behrens et al., 2000; Weiger et al., 2000; Brenner et al., 2005). However, BK channel biophysicists generally find it convenient to record currents with symmetrical, high potassium concentrations (replacing external sodium with potassium). Surprisingly, recordings conducted at physiological external sodium, low external potassium concentration instead indicate that $\beta 4$ confers a negative shift of the G-V relationship at all calcium concentrations (Wang et al., 2009; Jaffe et al., 2011) (Figure 3C). This casts some doubt into conclusions obtained from previous biophysical studies using non-physiological solutions. The slow activation and deactivation gating kinetics nevertheless is observed, albeit to a lesser extent (Figure 3D). Thus, from a steady-state perspective $\beta 4$ generally promotes $\mathrm{BK}$ channel opening. However, during the fast times of an action potential, the slow-activation conferred by

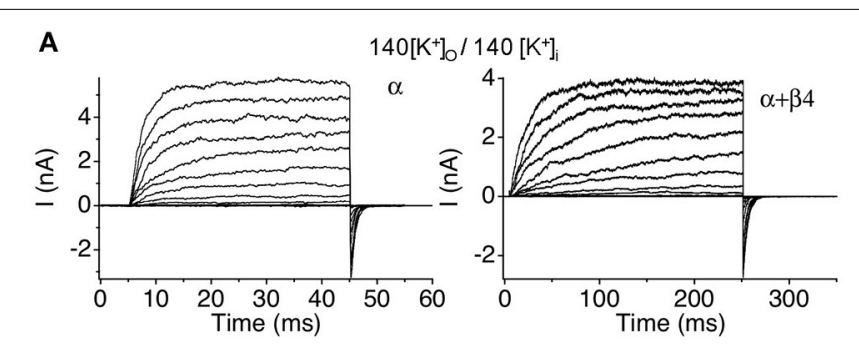

C

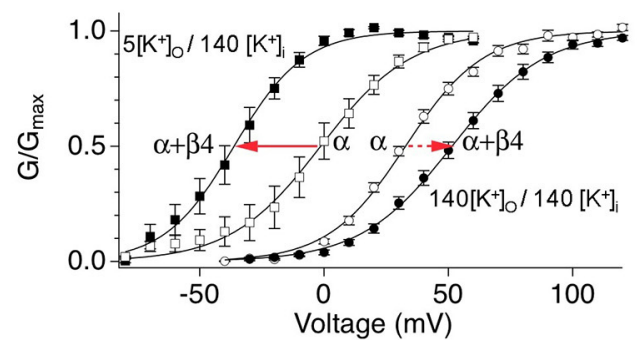

FIGURE 3 | Steady-state and kinetic properties of BK/ $\beta 4$ channels. Macroscopic recording comparing $\alpha$ alone and $\alpha+\beta 4$ channels in (A) symmetrical high external potassium ( $140 \mathrm{mM}$ outside/140 inside) to recordings in (B) asymmetrical $5 \mathrm{mM}$ external/140 $\mathrm{mM}$ internal potassium. (C) G-V relations. (D) Activation kinetics. Currents were

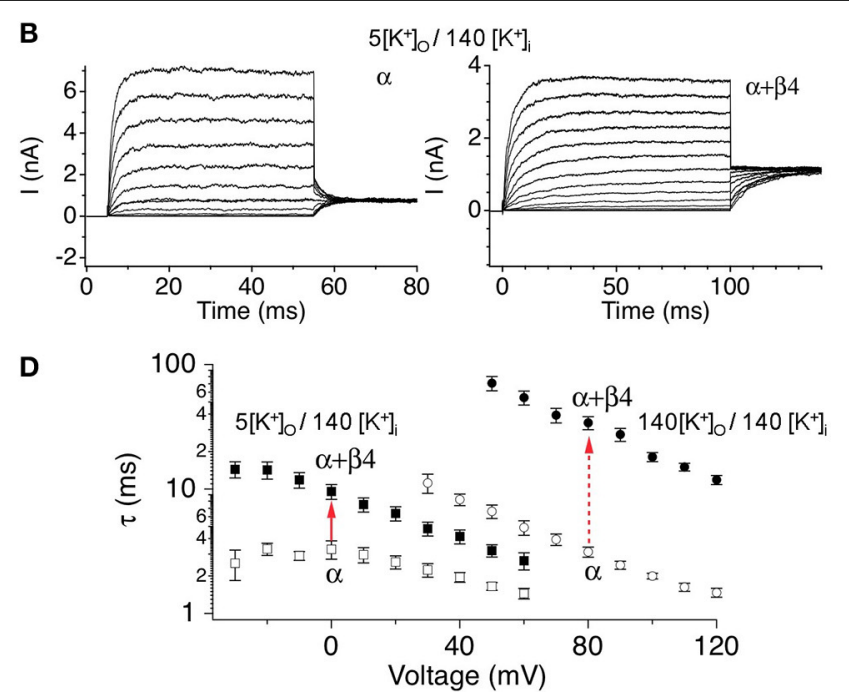

acquired at $7 \mu \mathrm{M}$ buffered internal calcium. Arrows indicate effect of $\beta 4$ on BK channels in physiological asymmetric potassium (solid arrows) or in non-physiological symmetrical potassium (dashed arrows). Data are replotted from Wang et al. (2009) and Jaffe et al. (2011). 
$\beta 4$ could theoretically inhibit BK channels from contributing to repolarization, whereas their slow-deactivation might sustain open channels following repolarization.

\section{$\beta 4$ EFFECTS ON BK CHANNELS IN THE CONTEXT OF BK $\alpha$ SUBUNIT ALTERNATIVE SPLICING OR GENE MUTATIONS}

The effect of $\beta 4$ on BK channel biophysical properties is also dependent on splicing isoforms or mutations of the $\alpha$ subunit. One well-studied splice variant is the stress-axis activated exon (STREX) (Xie and McCobb, 1998; Tian et al., 2001) that promotes BK channel opening via decreasing the closing rates of the channels. While $\beta 4$ and STREX both slow deactivation, the combined effect of STREX and $\beta 4$ are to speed deactivation (Petrik and Brenner, 2007). In addition, at low calcium, $\beta 4$ further inhibits channel opening of STREX channels by dramatically slowing channel activation kinetics (Petrik and Brenner, 2007). Studies of the inhibitory "SRKR" exon of BK channels also showed a more dramatic inhibition when coexpressed with $\beta 4$ (Shelley et al., 2013). Given its expression in the CNS, the effect of $\beta 4$ on a human mutation (D434G) that causes epilepsy and paroxysmal dyskinesia (Du et al., 2005) has also been studied (Du et al., 2005). The mutation dramatically increases BK channel openings and speeds channel activation. However, $\beta 4$ effects on steadystate, conductance-voltage relations is largely reduced with the human D434G mutation (Diez-Sampedro et al., 2006; Lee and Cui, 2009; Wang et al., 2009). Paradoxically, the mutation in the murine $\alpha$ (D369G) and $\beta 4$ channel subunit shows full effects of $\beta 4$. Why murine and human channels behave differently with regard to $\beta 4$ effects on the epilepsy $D / G$ mutation is currently unknown.

\section{BIOPHYSICAL NEURONAL MODELS CONTAINING TYPE I AND TYPE II BK CHANNELS}

Computer models of excitable cells containing BK channels have been used to understand the differential effects of inactivating and non-inactivating channels on output firing patterns. In adrenal chromaffin cells inactivating $\mathrm{BK}$ channels (containing $\alpha+\beta 2$ subunits) enhance excitability (Sun et al., 2009) by boosting the afterhyperpolarization (AHP) and, in turn, presumably enhancing the recovery of $\mathrm{Na}^{+}$channels from inactivation (Erisir et al., 1999). Modeling of inactivating BK channels in simulations of CA1 pyramidal neuron firing reproduces the decreased spike duration seen in the first few action potentials in a train of spikes (Shao et al., 1999). As discussed above, this allows for greater instantaneous firing rates at the beginning of an episode of spike generation.

The role of iberiotoxin-resistant (type II) BK channels on neuronal excitability has also been investigated by us in the modeling of BK channels in dentate gyrus granule neurons (Jaffe et al., 2011). Using physiological-appropriate recordings of type I ( $\alpha$ alone) and type II $(\alpha+\beta 4)$ BK channels in vitro, the investigators developed analytical equations describing the combined voltage-, calcium-, and time-dependence of both type I and II BK channels (Figure 4A). These were incorporated into a model of DG neurons containing either type I or type II channels (Jaffe et al., 2011). The model reproduced in silico the relative reduction in spike duration shaped by type I BK channels (Figure 4B1), similar to that observed from recordings of DG neurons where the $\beta 4$ was knocked out (Brenner et al., 2005). In contrast, type II channels achieved less spike reduction; $\sim 50 \%$ of that produced by type I channels (assuming the same BK channel density) because of the relative difference in activated BK channel current (Figure 4B2). The difference in BK current between the two channel types was readily explained by the difference in BK channel kinetics. The ratio of the steady-state activation variable plotted against the activation time constant variable $\left(w_{\infty} / \tau_{w}\right)$ illustrates a greater likelihood for type I channel activation for the short period of depolarization during peak of the action potential. It was not during the down-stroke of the spike where $\mathrm{Ca}^{2+}$ influx is maximal (Figure 4C). At the peak of the spike the initial influx of calcium reaches a concentration where it shifts the channels' voltage-dependence into the voltage range of an action potential (see Figure 4A). As a result, type II channel activation lags compared to that of type I channels. Subsequently, their differential effects on spike waveform can, in turn, influence neuronal excitability by altering slower $\mathrm{Ca}^{2+}$-dependent conductances (Brenner et al., 2005; Jaffe et al., 2011; Ly et al., 2011), $\mathrm{Na}^{+}$influx and $\mathrm{Na}^{+}$-dependent conductances, as well as voltagegated potassium conductances (Shao et al., 1999). This model also supports the hypothesis that both type I and II BK channels express a low-affinity $\mathrm{Ca}^{2+}$ sensor (Schreiber and Salkoff, 1997; Zhang et al., 2001) and that they are in close physical proximity to voltage-gated $\mathrm{Ca}^{2+}$ channels (Marrion and Tavalin, 1998; Grunnet and Kaufmann, 2004; Berkefeld et al., 2006; Muller et al., 2007). In particular, this model is highly consistent with the modeling of Engbers et al. (2013) where $\mathrm{Ca}^{2+}$ concentrations of $10 \mu \mathrm{M}$ or greater were required to observe a significant difference in spike duration (Figures 4B3,D).

\section{$\beta 4$ SURFACE TRAFFICKING IS HIGHLY REGULATED}

Considering the very broad and high level of $\beta 4 \mathrm{mRNA}$ throughout the brain (Behrens et al., 2000; Brenner et al., 2000; Meera et al., 2000; Uebele et al., 2000; Weiger et al., 2000) it is quite surprising that iberiotoxin-resistant BK channels have been described in only few types of neurons. These are cerebellar purkinje neurons (Benton et al., 2013), dentate gyrus neuronal soma (Brenner et al., 2005) and their mossy fiber terminals (Alle et al., 2011), and posterior pituitary terminals (Wang et al., 1992). One may conclude that $B K / \beta 4$ channel surface trafficking must be post-transcriptionally regulated. Recent studies indeed suggest that $\beta 4$ subunits are largely retained in intracellular compartments through an endoplasmic reticulum (ER) retention signal (Bai et al., 2011; Shruti et al., 2012; Cox et al., 2014). The efficiency of $\mathrm{BK} / \beta 4$ channels surface trafficking is controversial. Studies in transfected HEK293 cells by one group indicated that while $\beta 4$ is retained in the ER, it did not affect BK channel surface trafficking (Cox et al., 2014). While another group indeed showed a dominant negative effect of $\beta 4$ on BK channel surface trafficking in HEK293 cells and CA3 neurons (Shruti et al., 2012).

In addition to an ER retention motif (Shruti et al., 2012; Cox et al., 2014), the $\beta 4$ subunit was shown to be palmitoylated at a site in the carboxyl terminal cysteine 193 that is necessary for surface trafficking (Chen et al., 2013). Palmitoylated $\beta 4$ appears to oppose a $\mathrm{BK}$ channel splice variant retention signal 


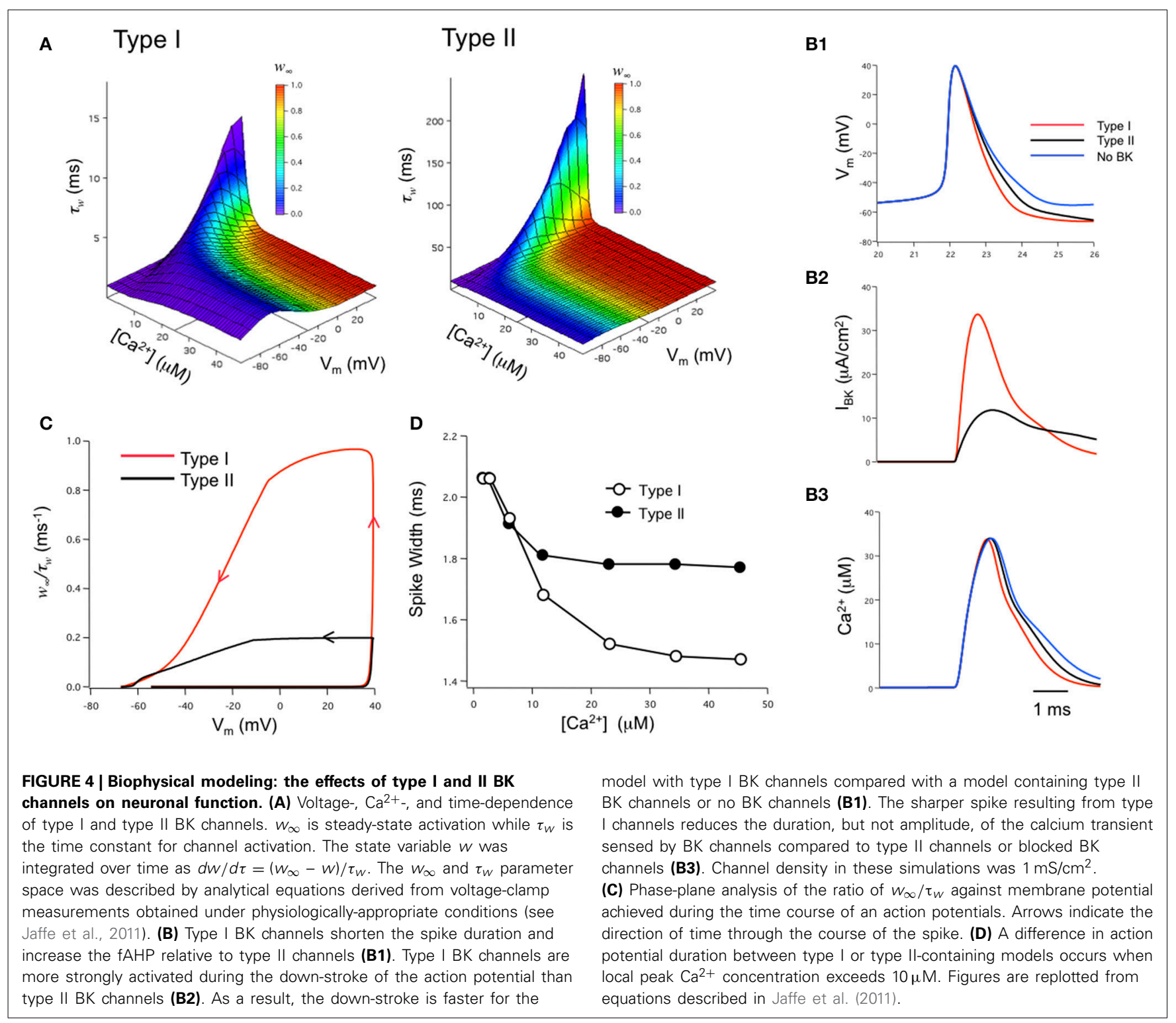

(VEDEC carboxyl variant) and thereby increase surface expression of this splice variant. For BK channel splice variants that lack this alternative splice site but are not maximally trafficked to the surface, palmitoylated $\beta 4$ does not promote surface expression but depalmitoylated $\beta 4$ subunits appear to retain channels in the ER. Thus, differences in neuronal palmitoylation, or BK channel splicing, might explain the paradoxical finding that although $\beta 4$ mRNA is more abundant in CA3 than dentate gyrus neurons, patch clamp recording show a largely iberiotoxin-sensitive current in CA3 and iberiotoxin-resistant current in DG neurons (Shruti et al., 2012).

\section{B4 SUBUNIT REGULATION BY STEROID HORMONES AND FATTY ACIDS}

Steroids have been known to modulate BK channels through nongenomic actions. Particularly the $\beta 1$ subunit, that is enriched in vascular smooth muscle, has drawn extensive attention given that it can directly interact with estrogen compounds (Valverde et al., 1999; Dick et al., 2001), activate smooth muscle BK channels (Dick and Sanders, 2001) and potentially have beneficial effects on vascular function. BK channels in the CNS (area postrema) have also shown to be activated by estrogen compounds (Li and Hay, 2000). However, it is often unclear whether these are direct effects or indirect effects since estrogen acutely modulates a large number of targets including protein kinase $G$, which also activates BK channels (Rosenfeld et al., 2000; White et al., 2002; Dimitropoulou et al., 2005). Nevertheless, early cloning and expression of the $\beta 4$ subunit showed that estrogen could, similar to $\beta 1$, activate $B K / \beta 4$ channels (Behrens et al., 2000). A comparative study of different steroids indicated the $\beta 4$ conferred a greater sensitivity to $\mathrm{BK}$ channels for corticosterone than estrogen, and followed by progesterone (King et al., 2006). This is in contrast to the $\beta 2$ subunit that is much less sensitive to corticosterone but activated by dehydroepiandrosterone (DHEA), a stress-related 
adrenal androgen. The differential sensitivities to corticosterone and DHEA provide an interesting opportunity to differentially activate $B K / \beta 4$ and $B K / \beta 2$ channels in neurons. The effect of corticosterone $(1 \mu \mathrm{M})$ on $B K / \beta 4$ channels was to negative-shift the conductance-voltage relations $(-13 \mathrm{mV})$ and slow deactivation kinetics about 3 fold (at $-80 \mathrm{mV}, 1 \mu \mathrm{M}$ internal calcium) (King et al., 2006). In addition to steroid hormones, some $\beta$ subunits also confer sensitivity to fatty acids. Recent studies showed that $\beta 4$, like $\beta 1$ but not $\beta 2$ confer a sensitivity to $\mathrm{BK}$ channels for the long chain omega-3 fatty acid, docosahexaenoic acid (DHA) (Hoshi et al., 2013). This is one of the fatty acid compounds enriched in fish oil that provides beneficial health effects (Harris et al., 2013). DHA $(3 \mu \mathrm{M})$ causes a robust $\sim-60 \mathrm{mV}$ shift of conductance-voltage relations in $\mathrm{BK} / \beta 4$ channels (measured in absence of calcium), but only $\sim-10 \mathrm{mV}$ shift in BK channels lacking $\beta$ subunits (Hoshi et al., 2013).

\section{PHYSIOLOGICAL FUNCTION OF IBERIOTOXIN-RESISTANT BK CHANNELS IN NEURONS B4 DISTRIBUTION IN THE BRAIN}

While BK channels expression in many regions of the nervous system is well-established (Wanner et al., 1999), the expression of $\beta 4$ needs further study. Gene targeting of an EGFP reporter into the KCNMB4 ( $\beta 4$ gene) locus, and in situ hybridization studies have provided some information regarding regions of high $\beta 4$ mRNA expression (Weiger et al., 2000; Brenner et al., 2005; Petrik and Brenner, 2007; Shruti et al., 2012). Using these approaches, $\beta 4$ shows strong staining in the posterior pituitary (Brenner et al., 2005), pyramidal neurons of the cortex, CA3 pyramidal neurons, and dentate gyrus region of the hippocampus (Weiger et al., 2000; Brenner et al., 2005; Petrik and Brenner, 2007; Shruti et al., 2012), olfactory bulb, and purkinje neurons of the cerebellum (Petrik and Brenner, 2007). To date, expression data is corroborated by functional studies of $B K / \beta 4$ channels in the posterior pituitary, CA3 pyramidal neurons, dentate gyrus granule neurons, and cerebellar purkinje neurons (will be discussed further below). In contrast to $\beta 4 \mathrm{mRNA}$, reports of immunolocalization of the protein in neurons is limited (Piwonska et al., 2008). In part, this is because antibodies to this protein, although commercially available, often lack sufficient specificity to unambiguously identify $\beta 4$ (a personal observation that many commercial anti- $\beta 4$ antibodies detect equivalent signals in our $\beta 4$ knockout mice).

\section{POSTERIOR PITUITARY TERMINALS}

Physiological function of BK/ $\beta 4$ channels was likely first studied in posterior pituitary nerve terminals (Bielefeldt and Jackson, 1993). The investigators described a calcium- and voltageactivated, large conductance potassium current that was resistant to charybdotoxin and apamin in rat posterior pituitary terminals (Bielefeldt et al., 1992). These characteristics strongly suggest $\mathrm{BK} / \beta 4$ channels, and indeed $\beta 4$ gene expression was later observed in posterior pituitary nerve terminals (Brenner et al., 2005). The investigators found that high frequency firing of action potentials was terminated by increased calcium influx using the L-type calcium channel opener Bay K 8644, presumably through activation of the calcium-activated potassium channels. A key observation was that these calcium-activated potassium channels were particularly slow- activated and deactivated. Thus, the investigators suggested that these channels are tailored for silencing bursts of action potentials that might arise possibly due to calcium accumulation. Later studies showed that while iberiotoxin-resistant BK channels are enriched in the pituitary terminals, BK channels of the hypothalamic somas that connect to these terminals are fast-gated, iberiotoxin-sensitive type I channels (Dopico et al., 1999). These results indicate that neurons may co-express distinct BK channel subtypes in different subcompartments,

\section{CEREBELLAR PURKINJE NEURONS}

BK channels likely have an important role in the cerebellum since knockout of the pore-forming subunit causes a profound ataxia in the mice (Meredith et al., 2004; Sausbier et al., 2004). Similar to hypothalamic neurons, a mixture of BK channel subtypes were recently identified in cerebellar purkinje neurons (Benton et al., 2013). However, the different subtypes did not appear to be segregated to different compartments. Whole cell recordings identified a mixture of slow-gated, non-inactivating iberiotoxin-resistant channels, and fast-gated, inactivating iberiotoxin-sensitive BK channels (Benton et al., 2013). The presence of iberiotoxinresistant $\mathrm{BK}$ channels is consistent with expression of $\beta 4$ in cerebellar purkinje neurons (Petrik and Brenner, 2007). The slowgating of the iberiotoxin-resistant BK channels sustains opening of these channels during the AHP and contributes to a sustained interspike conductance (Benton et al., 2013). Unfortunately, the investigators did not specifically block these channels and not the inactivating subtype to investigate the consequence of the iberiotoxin-resistant currents on firing frequency. However, they had the novel observation that the SK channel agonist EBIO is an agonist for iberiotoxin-resistant channels, and indeed observed a larger interspike conductance and reduced spike frequency with EBIO. Given that SK current is inconsequential in the age of neurons studied, then the effect of EBIO was attributed to the $B K / \beta 4$ channels. Teleologically, one can make the observation that $\mathrm{BK} / \beta 4$ are being employed to replace the calcium-activated, SK-type potassium channels that similarly have sustained interspike openings that allows for effective regulation of spike frequency (Sah and Faber, 2002). Despite the fact that knockout of the BK channel pore-forming subunit causes a profound ataxia (Meredith et al., 2004; Sausbier et al., 2004), the role of the $\beta 4$ accessory subunit in the cerebellum is either more subtle or somewhat different since an ataxic phenotype has not been reported in $\beta 4$ knockout mice.

\section{CA3 HIPPOCAMPUS NEURONS}

In situ hybridization reported by investigators (Shruti et al., 2012) and the Allen Brain Atlas (http://mouse.brain-map.org/ gene/show/37365) indicate greatest expression of $\beta 4$ mRNA in CA3 neurons. Utilizing a gene knockout for the Fragile X Mental Retardation Protein (FMRP), it was recently found that this protein regulates action potential duration through direct interactions with the $\beta 4$ subunit (Deng et al., 2013). The FMRP gene is essential for cognitive development and strongly linked to mental disabilities and autism (Wijetunge et al., 2013). Knockout of the FMRP gene was found to cause broadening of action potentials and reduced fast-afterhyperpolarizations. Knockout of $\beta 4$ 
occludes FMRP protein effects on action potential duration. The authors demonstrated that the effect on action potential duration consequently affects calcium influx and neurotransmitter release at CA3-CA1 synapses. This novel finding suggests that the $\beta 4$ protein, through interactions with FMRP, might be a direct mediator of BK channel regulation in cognitive function.

The findings of Deng et al. (2013) also pose some interesting questions. Despite a key role of $\beta 4$ subunits in mediating effects of FMRP on action potentials, iberiotoxin apparently blocked these channels in CA3 neurons (Deng et al., 2013). This was a similar finding as Shruti et al. (2012). It is therefore not clear how $\mathrm{BK} / \beta 4$ might regulate action potential shape, yet be sensitive to iberiotoxin. BK channels are homotetramers and are believed to express a theoretical four or less $\beta$ subunits (Ding et al., 1998; Wang et al., 2002). As yet we do not know the stoichiometry of BK $\alpha$ and $\beta 4$ subunits sufficient to confer iberiotoxin resistance. One might speculate that in CA3 neurons, membrane-associated BK channels might have a less than saturating concentration of $\beta 4$ subunits that perhaps allow access of iberiotoxin to the BK channel pore, whilst still modulating BK channel activity. Given that knockout of the $\beta 4$ gene appears to allow greater trafficking of channels to the membrane (Shruti et al., 2012), one might also speculate that FMRP may function to retain more $\beta 4$ subunits in the ER in some neurons such as CA3, to allow $\mathrm{BK}$ channels to be fast-gated and more effectively shape action potentials.

\section{DENTATE GYRUS GRANULE NEURONS}

Dentate gyrus neurons in mice express predominantly iberiotoxin-resistant, type II channels as evidenced by whole cell current recordings (Shruti et al., 2012) and single channel recordings (Brenner et al., 2005). Presumably due to the slow gating, blocking these channels with paxilline had no significant affect on action potential shape (WT red trace vs. WTPax red dashed trace, Figure 5) (Brenner et al., 2005). Knockout of $\beta 4$ results in a conversion to type $\mathrm{I}$, iberiotoxin-sensitive channels and a BK channel gain-of-function as evidenced by sharper action potentials and a larger fast-afterhyperpolarization (Figure 5). The greater contribution to action potential repolarization in the $\beta 4 \mathrm{KO}$ is largely consistent with the computational predictions of Jaffe et al. (2011), and discussed above. Evidence that $\beta 4$ knockout results in a gain-of-function of BK channels is apparent from paxilline block of $\mathrm{KO}$ neurons, which broadens the action potential trace to that of wild type (Figure 5). It is important to point out that in other studies paxilline shows a greater effect on BK-mediated repolarization in recordings of wild type rat dentate gyrus neurons (Muller et al., 2007). This is perhaps due to warmer recording conditions $\left(35^{\circ} \mathrm{C}\right)$ that likely speeds $\mathrm{BK} / \beta 4$ channel gating, compared to the $25^{\circ} \mathrm{C}$ recording conditions in the mouse KO studies (Brenner et al., 2005). The relative contribution to action potential repolarization of BK channels in wild type vs. $\beta 4 \mathrm{KO}$ neurons at near physiological temperatures has yet to be determined.

A surprising observation was that the $\beta 4$ knockout conversion to type I, fast-gated BK channels increased the action potential frequency in dentate gyrus neurons and resulted in spontaneous temporal lobe seizures in the mice (Brenner et al., 2005). A similar

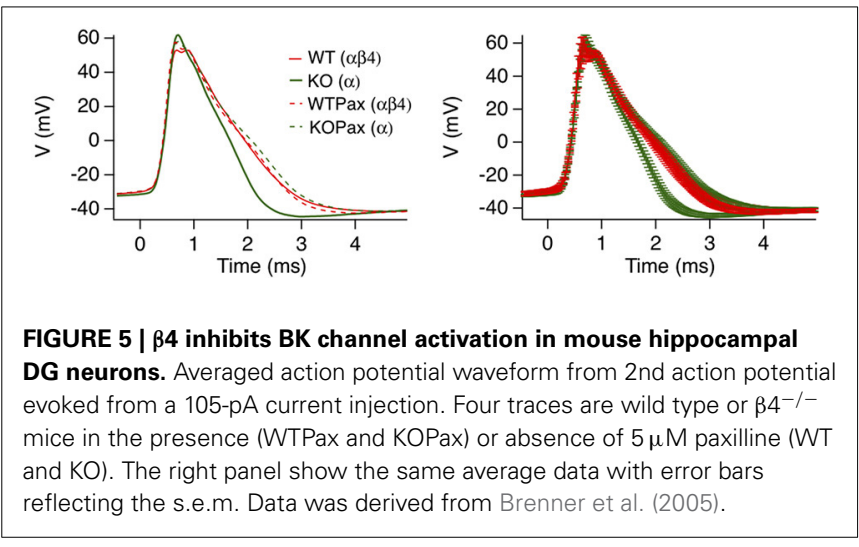

effect has been seen with a human gain-of-function mutation of the pore-forming $\alpha$ subunit that results in epilepsy in family members carrying the mutant allele (Du et al., 2005). As well, pro-excitatory BK channels appear to be acquired in a picrotoxin seizure model (Shruti et al., 2008), and paxilline block of these channels appears to protect against subsequent seizures following a second insult (Sheehan et al., 2009). Thus, one may conclude that fast-gated BK channels can be pro-excitatory and slowing of BK channels with $\beta 4$ can reduce excitability. The pro-excitatory mechanisms of BK channels need to be further studied. But they may be mediated by secondary effects of fast-gated BK channel: a sharper action potential or larger fAHP that would theoretically remove sodium channel inactivation or reduce activation of other potassium currents such as delayed rectifier currents $(\mathrm{Gu}$ et al., 2007) or SK-type calcium activated currents (Brenner et al., 2005), that otherwise reduce spike frequency.

\section{PRESYNAPTIC BK/B4 CHANNELS}

Axons of dentate gyrus granule cells, the mossy fibers, have very large presynaptic terminals that provide one of the few opportunities in central neurons (in addition to the calyx of held and posterior pituitary terminals) where voltage clamping of a presynaptic terminal is feasible. Recordings of mossy fiber terminals identified a mixture of iberiotoxin-sensitive and iberiotoxinresistant $\mathrm{BK}$ channels suggesting that the $\beta 4$ subunit also traffic to presynaptic locations (Alle et al., 2011). Similar to purkinje neurons discussed above, the iberiotoxin-sensitive fraction was fast-gated, and inactivating. The iberiotoxin-resistant fraction were slow-gated, typical of BK/ $\beta 4$ type II channels. Interestingly, even the fast-gated BK channel subtype could not contribute to presynaptic terminal action potential repolarization owing to the faster-gating of Kv3 type channels that dominate the presynaptic repolarization. Similar to studies in Schaffer collateralcommissural fibers (Hu et al., 2001), a role for mossy fiber terminal BK channels was revealed only when $\mathrm{Kv}$ channels were first blocked (Alle et al., 2011). By showing that even the fast BK component was sensitive to a slow calcium buffer (EGTA), the investigators concluded that slow-activation of presynaptic BK channels might also be due to a lack of nanodomain calcium source required for fast BK channel activation. In contrast, somatic BK channels were reported to be insensitive to EGTA or even moderate concentrations of fast chelator BAPTA (Muller 
et al., 2007) indicating somatic BK channels are distinguished from terminal BK channels, not only in being more homogeneously composed of BK/ $\beta 4$ channels (Brenner et al., 2005; Shruti et al., 2012), but also being more tightly coupled to their calcium source (Muller et al., 2007).

\section{SUMMARY AND FUTURE DIRECTIONS}

Our understanding of BK channel subtypes appears to be shifting from ascribing different BK channel subtypes in different neurons, to different BK channel subtypes cohabitating neurons. As well, we are beginning to recognize how different subtypes are employed toward the needs of the cell. BK/ $\beta 4$ may coexist with other subtypes in a single compartment, such as inactivating $\mathrm{BK}$ channels and $\mathrm{BK} / \beta 4$ channels in mossy fiber presynaptic terminals (Alle et al., 2011) and pyramidal neuronal soma (Benton et al., 2013). Alternatively, BK/ $\beta 4$ channels may be segregated to different subcompartments, such as fast-gated type I channels in hypothalamic magnocellular neurons in the soma, and type II BK/ $\beta 4$ channels residing only in their posterior pituitary terminals. In general, slow-gating by $\beta 4$ appears to either reduce $\mathrm{BK}$ channel contribution to action potentials or contribute to a more sustained interspike conductance while the fast-gated BK channels having a more conventional role to shape action potentials. Finally, the $\beta 4$ subunit has roles in addition to modulating $\mathrm{BK}$ channel biophysical properties that include regulation of BK channel surface trafficking and as a receptor for other proteins such as FMRP to modulate BK channels.

There is much more that is necessary to understand with regard to the nature of iberiotoxin-resistant BK channels. Studies of $\beta 1$ and $\beta 2$ stoichiometry indicate that BK channels can assemble with a less than saturating (four or less subunits per channel) concentration of $\beta$ subunits (Ding et al., 1998; Wang et al., 2002) resulting in intermediate gating properties than is expected from fully $\beta$-saturated channels (Ding et al., 1998; Wang et al., 2002). One might speculate that a less than saturating concentration of $\beta 4$ might not occlude iberiotoxin access, and therefore $\beta 4$ might also be assembled with BK channels more broadly in the nervous system than we can infer from the iberiotoxin-resistant pharmacology. This might explain why $\beta 4$ subunit mRNA is broadly expressed (Brenner et al., 2000), yet iberiotoxin-resistant channels seem to be more restricted, and mainly seen in neurons that have relatively high expression levels of $\beta 4$. Further, we do not yet know if BK channels can assemble to include mixtures of accessory subunits, such as both $\beta 2$ and $\beta 4$ subunits, to further increase BK channel diversity. Certainly, future studies are needed to better understand the pharmacology of $\mathrm{BK} / \beta 4$ channels with subsaturating $\beta 4$ accessory subunits, or with coexpressed $\beta 2$ and $\beta 4$ subunits, so that we can relate this to the molecular underpinnings of these channels in neurons. One should expect that our understanding of the functional role of iberiotoxin-resistant BK channels should improve as utilization of $\mathrm{BK} / \beta 4$-specific toxin Mallotoxin will allow investigation of these channels specifically, without blocking all $\mathrm{BK}$ channels. As well, our understanding of BK/ $\beta 4$ channels should increase as the $\beta 4$ knockout mice are employed to a greater extent.

\section{ACKNOWLEDGMENTS}

Robert Brenner was supported by the Research Enhancement Program of the University of Texas Health Science Center at San Antonio, and by NIH grant 1R21AI113724.

\section{REFERENCES}

Alle, H., Kubota, H., and Geiger, J. R. (2011). Sparse but highly efficient Kv3 outpace BKCa channels in action potential repolarization at hippocampal mossy fiber boutons. J. Neurosci. 31, 8001-8012. doi: 10.1523/JNEUROSCI.097211.2011

Bai, J. P., Surguchev, A., and Navaratnam, D. (2011). beta4-subunit increases Slo responsiveness to physiological $\mathrm{Ca} 2+$ concentrations and together with beta1 reduces surface expression of Slo in hair cells. Am. J. Physiol. Cell Physiol. 300, C435-C446. doi: 10.1152/ajpcell.00449.2010

Bao, L., and Cox, D. H. (2005). Gating and ionic currents reveal how the BKCa channel's Ca2+ sensitivity is enhanced by its \{beta\}1 subunit. J. Gen. Physiol. 126, 393-412. doi: 10.1085/jgp.200509346

Bao, L., Rapin, A. M., Holmstrand, E. C., and Cox, D. H. (2002). Elimination of the $\mathrm{BK}(\mathrm{Ca})$ channel's high-affinity $\mathrm{Ca}(2+)$ sensitivity. J. Gen. Physiol. 120, 173-189. doi: 10.1085/jgp.20028627

Behrens, R., Nolting, A., Reimann, F., Schwarz, M., Waldschutz, R., and Pongs, O. (2000). hKCNMB3 and hKCNMB4, cloning and characterization of two members of the large-conductance calcium-activated potassium channel beta subunit family. FEBS Lett. 474, 99-106. doi: 10.1016/S0014-5793(00)01584-2

Benton, M. D., Lewis, A. H., Bant, J. S., and Raman, I. M. (2013) Iberiotoxin-sensitive and -insensitive BK currents in Purkinje neuron somata. J. Neurophysiol. 109, 2528-2541. doi: 10.1152/jn.00127.2012

Berkefeld, H., Sailer, C. A., Bildl, W., Rohde, V., Thumfart, J. O., Eble, S., et al. (2006). BKCa-Cav channel complexes mediate rapid and localized $\mathrm{Ca}^{2+}$ activated K+ signaling. Science 314, 615-620. doi: 10.1126/science.1132915

Bielefeldt, K., and Jackson, M. B. (1993). A calcium-activated potassium channel causes frequency-dependent action-potential failures in a mammalian nerve terminal. J. Neurophysiol. 70, 284-298.

Bielefeldt, K., Rotter, J. L., and Jackson, M. B. (1992). Three potassium channels in rat posterior pituitary nerve terminals. J. Physiol. 458, 41-67.

Brenner, R., Chen, Q. H., Vilaythong, A., Toney, G. M., Noebels, J. L., and Aldrich, R. W. (2005). BK channel beta4 subunit reduces dentate gyrus excitability and protects against temporal lobe seizures. Nat. Neurosci. 8, 1752-1759. doi: 10.1038/nn1573

Brenner, R., Jegla, T. J., Wickenden, A., Liu, Y., and Aldrich, R. W. (2000). Cloning and functional characterization of novel large conductance calcium-activated potassium channel beta subunits, hKCNMB3 and hKCNMB4. J. Biol. Chem. 275, 6453-6461. doi: 10.1074/jbc.275.9.6453

Calderone, V. (2002). Large-conductance, $\mathrm{ca}(2+)$-activated $\mathrm{k}(+)$ channels: function, pharmacology and drugs. Curr. Med. Chem. 9, 1385-1395. doi: 10.2174/0929867023369871

Chen, L., Bi, D., Tian, L., McClafferty, H., Steeb, F., Ruth, P., et al. (2013). Palmitoylation of the beta4-subunit regulates surface expression of large conductance calcium-activated potassium channel splice variants. J. Biol. Chem. 288, 13136-13144. doi: 10.1074/jbc.M113.461830

Contreras, G. F., Neely, A., Alvarez, O., Gonzalez, C., and Latorre, R. (2012). Modulation of BK channel voltage gating by different auxiliary beta subunits. Proc. Natl. Acad. Sci. U.S.A. 109, 18991-18996. doi: 10.1073/pnas.12169 53109

Cox, D. H., Cui, J., and Aldrich, R. W. (1997). Allosteric gating of a large conductance Ca-activated K+ channel. J. Gen. Physiol. 110, 257-281. doi: 10.1085/jgp.110.3.257

Cox, N., Toro, B., Pacheco-Otalora, L. F., Garrido-Sanabria, E. R., and Zarei, M. M. (2014). An endoplasmic reticulum trafficking signal regulates surface expression of beta 4 subunit of a voltage- and $\mathrm{Ca}(2)(+)$-activated $\mathrm{K}(+)$ channel. Brain Res. 1553, 12-23. doi: 10.1016/j.brainres.2014.01.028

Cui, J., Cox, D. H., and Aldrich, R. W. (1997). Intrinsic voltage dependence and $\mathrm{Ca} 2+$ regulation of mslo large conductance Ca-activated K+ channels. J. Gen. Physiol. 109, 647-673. doi: 10.1085/jgp.109.5.647

Deng, P. Y., Rotman, Z., Blundon, J. A., Cho, Y., Cui, J., Cavalli, V., et al. (2013). FMRP regulates neurotransmitter release and synaptic information transmission by modulating action potential duration via BK channels. Neuron 77, 696-711. doi: 10.1016/j.neuron.2012.12.018 
Dick, G. M., Rossow, C. F., Smirnov, S., Horowitz, B., and Sanders, K. M. (2001). Tamoxifen activates smooth muscle BK channels through the regulatory beta 1 subunit. J. Biol. Chem. 276, 34594-34599. doi: 10.1074/jbc.M104689200

Dick, G. M., and Sanders, K. M. (2001). (Xeno)estrogen sensitivity of smooth muscle BK channels conferred by the regulatory betal subunit: a study of betal knockout mice. J. Biol. Chem. 276, 44835-44840. doi: 10.1074/jbc.M106851200

Diez-Sampedro, A., Silverman, W. R., Bautista, J. F., and Richerson, G. B. (2006). Mechanism of increased open probability by a mutation of the BK channel. J. Neurophysiol. 96, 1507-1516. doi: 10.1152/jn.00461.2006

Dimitropoulou, C., White, R. E., Ownby, D. R., and Catravas, J. D. (2005). Estrogen reduces carbachol-induced constriction of asthmatic airways by stimulating large-conductance voltage and calcium-dependent potassium channels. Am. J. Respir. Cell Mol. Biol. 32, 239-247. doi: 10.1165/rcmb.2004-0331OC

Ding, J. P., Li, Z. W., and Lingle, C. J. (1998). Inactivating BK channels in rat chromaffin cells may arise from heteromultimeric assembly of distinct inactivation-competent and noninactivating subunits. Biophys. J. 74, 268-289. doi: 10.1016/S0006-3495(98)77785-9

Dopico, A. M., Widmer, H., Wang, G., Lemos, J. R., and Treistman, S. N. (1999). Rat supraoptic magnocellular neurones show distinct large conductance, $\mathrm{Ca} 2+-$ activated $\mathrm{K}+$ channel subtypes in cell bodies versus nerve endings. J. Physiol. 519 Pt 1, 101-114. doi: 10.1111/j.1469-7793.1999.0101o.x

Du, W., Bautista, J. F., Yang, H., Diez-Sampedro, A., You, S. A., Wang, L., et al. (2005). Calcium-sensitive potassium channelopathy in human epilepsy and paroxysmal movement disorder. Nat. Genet. 37, 733-738. doi: 10.1038/ng1585

Engbers, J. D., Zamponi, G. W., and Turner, R. W. (2013). Modeling interactions between voltage-gated $\mathrm{Ca}(2+)$ channels and KCa1.1 channels. Channels (Austin) 7, 524-529. doi: 10.4161/chan.25867

Erisir, A., Lau, D., Rudy, B., and Leonard, C. S. (1999). Function of specific $\mathrm{K}(+)$ channels in sustained high-frequency firing of fast-spiking neocortical interneurons. J. Neurophysiol. 82, 2476-2489.

Faber, E. S., and Sah, P. (2003). Ca2+-activated K+ (BK) channel inactivation contributes to spike broadening during repetitive firing in the rat lateral amygdala. J. Physiol. 552, 483-497. doi: 10.1113/jphysiol.2003.050120

Fakler, B., and Adelman, J. P. (2008). Control of K(Ca) channels by calcium nano/microdomains. Neuron 59, 873-881. doi: 10.1016/j.neuron.2008.09.001

Gan, G., Yi, H., Chen, M., Sun, L., Li, W., Wu, Y., et al. (2008). Structural basis for toxin resistance of beta4-associated calcium-activated potassium (BK) channels. J. Biol. Chem. 283, 24177-24184. doi: 10.1074/jbc.M800179200

Gribkoff, V. K., Starrett, J. E. Jr., and Dworetzky, S. I. (1997). The pharmacology and molecular biology of large-conductance calcium- activated (BK) potassium channels. Adv. Pharmacol. 37, 319-348. doi: 10.1016/S1054-3589(08)60954-0

Grunnet, M., and Kaufmann, W. A. (2004). Coassembly of big conductance $\mathrm{Ca}^{2+}$. activated $\mathrm{K}+$ channels and L-type voltage-gated $\mathrm{Ca}^{2+}$ channels in rat brain. J. Biol. Chem. 279, 36445-36453. doi: 10.1074/jbc.M402254200

$\mathrm{Gu}$, N., Vervaeke, K., and Storm, J. F. (2007). BK potassium channels facilitate high-frequency firing and cause early spike frequency adaptation in rat CA1 hippocampal pyramidal cells. J. Physiol. 580, 859-882. doi: 10.1113/jphysiol.2006.126367

Ha, T. S., Heo, M. S., and Park, C. S. (2004). Functional effects of auxiliary beta4subunit on rat large-conductance $\mathrm{Ca}(2+)$-activated $\mathrm{K}(+)$ channel. Biophys. J. 86, 2871-2882. doi: 10.1016/S0006-3495(04)74339-8

Harris, W. S., Dayspring, T. D., and Moran, T. J. (2013). Omega-3 fatty acids and cardiovascular disease: new developments and applications. Postgrad. Med. 125, 100-113. doi: 10.3810/pgm.2013.11.2717

Horrigan, F. T., and Aldrich, R. W. (1999). Allosteric voltage gating of potassium channels II. Mslo channel gating charge movement in the absence of $\mathrm{Ca}(2+)$. J. Gen. Physiol. 114, 305-336. doi: 10.1085/jgp.114.2.305

Horrigan, F. T., and Aldrich, R. W. (2002). Coupling between voltage sensor activation, $\mathrm{Ca} 2+$ binding and channel opening in large conductance $(\mathrm{BK})$ potassium channels. J. Gen. Physiol. 120, 267-305. doi: 10.1085/jgp.20028605

Horrigan, F. T., Cui, J., and Aldrich, R. W. (1999). Allosteric voltage gating of potassium channels I. Mslo ionic currents in the absence of $\mathrm{Ca}(2+)$. J. Gen. Physiol. 114, 277-304. doi: 10.1085/jgp.114.2.277

Hoshi, T., Tian, Y., Xu, R., Heinemann, S. H., and Hou, S. (2013). Mechanism of the modulation of BK potassium channel complexes with different auxiliary subunit compositions by the omega-3 fatty acid DHA. Proc. Natl. Acad. Sci. U.S.A. 110, 4822-4827. doi: 10.1073/pnas. 1222003110

Hu, H., Shao, L. R., Chavoshy, S., Gu, N., Trieb, M., Behrens, R., et al. (2001). Presynaptic Ca2+-activated K+ channels in glutamatergic hippocampal terminals and their role in spike repolarization and regulation of transmitter release. J. Neurosci. 21, 9585-9597.

Hu, S., Labuda, M. Z., Pandolfo, M., Goss, G. G., McDermid, H. E., and Ali, D. W. (2003). Variants of the KCNMB3 regulatory subunit of maxi BK channels affect channel inactivation. Physiol. Genomics 15, 191-198. doi: 10.1152/physiolgenomics.00110.2003

Jaffe, D. B., Wang, B., and Brenner, R. (2011). Shaping of action potentials by type I and type II large-conductance $\mathrm{Ca}(2)+$-activated $\mathrm{K}+$ channels. Neuroscience 192, 205-218. doi: 10.1016/j.neuroscience.2011.06.028

Ji, Y. H., Wang, W. X., Ye, J. G., He, L. L., Li, Y. J., Yan, Y. P., et al. (2003). Martentoxin, a novel K+-channel-blocking peptide: purification, cDNA and genomic cloning, and electrophysiological and pharmacological characterization. J. Neurochem. 84, 325-335. doi: 10.1046/j.1471-4159.2003. 01516.x

Kaczorowski, G. J., Knaus, H. G., Leonard, R. J., McManus, O. B., and Garcia, M. L. (1996). High-conductance calcium-activated potassium channels; structure, pharmacology, and function. J. Bioenerg. Biomembr. 28, 255-267. doi: 10.1007/BF02110699

King, J. T., Lovell, P. V., Rishniw, M., Kotlikoff, M. I., Zeeman, M. L., and McCobb, D. P. (2006). Beta2 and beta4 subunits of BK channels confer differential sensitivity to acute modulation by steroid hormones. J. Neurophysiol. 95, 2878-2888. doi: 10.1152/jn.01352.2005

Knaus, H. G., McManus, O. B., Lee, S. H., Schmalhofer, W. A., GarciaCalvo, M., Helms, L. M., et al. (1994). Tremorgenic indole alkaloids potently inhibit smooth muscle high-conductance calcium-activated potassium channels. Biochemistry 33, 5819-5828. doi: 10.1021/ bi00185a021

Lee, U. S., and Cui, J. (2009). \{beta\} subunit-specific modulations of BK channel function by a mutation associated with epilepsy and dyskinesia. J. Physiol. 587, 1481-1498. doi: 10.1113/jphysiol.2009.169243

Li, M., Chang, S., Yang, L., Shi, J., McFarland, K., Yang, X., et al. (2014). Conopeptide Vt3.1 preferentially inhibits $\mathrm{BK}$ potassium channels containing beta4 subunits via electrostatic interactions. J. Biol. Chem. 289, 4735-4742. doi: 10.1074/jbc.M113.535898

Li, Z., and Hay, M. (2000). 17-beta-estradiol modulation of area postrema potassium currents. J. Neurophysiol. 84, 1385-1391.

Lingle, C. J. (2002). Setting the stage for molecular dissection of the regulatory components of BK channels. J. Gen. Physiol. 120, 261-265. doi: 10.1085/jgp.20028689

Lippiat, J. D., Standen, N. B., Harrow, I. D., Phillips, S. C., and Davies, N. W. (2003). Properties of $\mathrm{BK}(\mathrm{Ca})$ channels formed by bicistronic expression of hSloalpha and beta1-4 subunits in HEK293 cells. J. Membr. Biol. 192, 141-148. doi: 10.1007/s00232-002-1070-0

Ly, C., Melman, T., Barth, A. L., and Ermentrout, G. B. (2011). Phase-resetting curve determines how BK currents affect neuronal firing. J. Comput. Neurosci. 30, 211-223. doi: 10.1007/s10827-010-0246-3

Ma, Z., Lou, X. J., and Horrigan, F. T. (2006). Role of charged residues in the S1-S4 voltage sensor of BK channels. J. Gen. Physiol. 127, 309-328. doi: 10.1085/jgp. 200509421

Marrion, N. V., and Tavalin, S. J. (1998). Selective activation of $\mathrm{Ca}^{2+}$-activated K+ channels by co-localized Ca2+ channels in hippocampal neurons. Nature 395, 900-905. doi: 10.1038/27674

McLarnon, J. G. (1995). Inactivation of a high conductance calcium dependent potassium current in rat hippocampal neurons. Neurosci. Lett. 193, 5-8. doi: 10.1016/0304-3940(95)11651-C

Meera, P., Wallner, M., and Toro, L. (2000). A neuronal beta subunit (KCNMB4) makes the large conductance, voltage- and $\mathrm{Ca} 2+$-activated $\mathrm{K}+$ channel resistant to charybdotoxin and iberiotoxin. Proc. Natl. Acad. Sci. U.S.A. 97, 5562-5567. doi: $10.1073 /$ pnas. 100118597

Meredith, A. L., Thorneloe, K. S., Werner, M. E., Nelson, M. T., and Aldrich, R. W. (2004). Overactive bladder and incontinence in the absence of the BK large conductance Ca2+-activated K+ channel. J. Biol. Chem. 279, 36746-36752. doi: 10.1074/jbc.M405621200

Muller, A., Kukley, M., Uebachs, M., Beck, H., and Dietrich, D. (2007). Nanodomains of single $\mathrm{Ca} 2+$ channels contribute to action potential repolarization in cortical neurons. J. Neurosci. 27, 483-495. doi: 10.1523/JNEUROSCI.3816-06.2007

Orio, P., and Latorre, R. (2005). Differential effects of beta 1 and beta 2 subunits on BK channel activity. J. Gen. Physiol. 125, 395-411. doi: 10.1085/jgp.200409236 
Orio, P., Rojas, P., Ferreira, G., and Latorre, R. (2002). New disguises for an old channel: MaxiK channel beta-subunits. News Physiol. Sci. 17, 156-161. doi: 10.1152/nips.01387.2002

Petrik, D., and Brenner, R. (2007). Regulation of STREX exon large conductance, calcium-activated potassium channels by the beta4 accessory subunit. Neuroscience 149, 789-803. doi: 10.1016/j.neuroscience.2007.07.066

Piwonska, M., Wilczek, E., Szewczyk, A., and Wilczynski, G. M. (2008). Differential distribution of $\mathrm{Ca} 2+$-activated potassium channel beta4 subunit in rat brain: immunolocalization in neuronal mitochondria. Neuroscience 153, 446-460. doi: 10.1016/j.neuroscience.2008.01.050

Reinhart, P. H., Chung, S., and Levitan, I. B. (1989). A family of calcium-dependent potassium channels from rat brain. Neuron 2, 1031-1041. doi: 10.1016/08966273(89)90227-4

Reinhart, P. H., and Levitan, I. B. (1995). Kinase and phosphatase activities intimately associated with a reconstituted calcium-dependent potassium channel. J. Neurosci. 15, 4572-4579.

Rosenfeld, C. R., White, R. E., Roy, T., and Cox, B. E. (2000). Calcium-activated potassium channels and nitric oxide coregulate estrogen-induced vasodilation. Am. J. Physiol. Heart Circ. Physiol. 279, H319-H328.

Rothberg, B. S., and Magleby, K. L. (1999). Gating kinetics of single largeconductance $\mathrm{Ca} 2+$-activated $\mathrm{K}+$ channels in high $\mathrm{Ca} 2+$ suggest a two-tiered allosteric gating mechanism [In Process Citation]. J. Gen. Physiol. 114, 93-124. doi: 10.1085/jgp.114.1.93

Sah, P., and Faber, E. S. (2002). Channels underlying neuronal calciumactivated potassium currents. Prog. Neurobiol. 66, 345-353. doi: 10.1016/S03010082(02)00004-7

Sausbier, M., Hu, H., Arntz, C., Feil, S., Kamm, S., Adelsberger, H., et al. (2004). Cerebellar ataxia and Purkinje cell dysfunction caused by $\mathrm{Ca} 2+$-activated K+ channel deficiency. Proc. Natl. Acad. Sci. U.S.A. 101, 9474-9478. doi: 10.1073/pnas.0401702101

Schreiber, M., and Salkoff, L. (1997). A novel calcium-sensing domain in the BK channel. Biophys. J. 73, 1355-1363. doi: 10.1016/S0006-3495(97)78168-2

Shao, L. R., Halvorsrud, R., Borg-Graham, L., and Storm, J. F. (1999). The role of BK-type $\mathrm{Ca} 2+$-dependent $\mathrm{K}+$ channels in spike broadening during repetitive firing in rat hippocampal pyramidal cells. J. Physiol. 521 Pt 1, 135-146. doi: 10.1111/j.1469-7793.1999.00135.x

Sheehan, J. J., Benedetti, B. L., and Barth, A. L. (2009). Anticonvulsant effects of the BK-channel antagonist paxilline. Epilepsia 50, 711-720. doi: 10.1111/j.15281167.2008.01888.x

Shelley, C., Whitt, J. P., Montgomery, J. R., and Meredith, A. L. (2013). Phosphorylation of a constitutive serine inhibits BK channel variants containing the alternate exon "SRKR." J. Gen. Physiol. 142, 585-598. doi: 10.1085/jgp.201311072

Shi, J., He, H. Q., Zhao, R., Duan, Y. H., Chen, J., Chen, Y., et al. (2008). Inhibition of martentoxin on neuronal BK channel subtype (alpha+beta4): implications for a novel interaction model. Biophys. J. 94, 3706-3713. doi: 10.1529/biophysj.107.122150

Shruti, S., Clem, R. L., and Barth, A. L. (2008). A seizure-induced gain-offunction in BK channels is associated with elevated firing activity in neocortical pyramidal neurons. Neurobiol. Dis. 30, 323-330. doi: 10.1016/j.nbd.2008. 02.002

Shruti, S., Urban-Ciecko, J., Fitzpatrick, J. A., Brenner, R., Bruchez, M. P., and Barth, A. L. (2012). The brain-specific Beta4 subunit downregulates BK channel cell surface expression. PLoS ONE 7:e33429. doi: 10.1371/journal.pone.0033429

Solaro, C. R., and Lingle, C. J. (1992). Trypsin-sensitive, rapid inactivation of a calcium-activated potassium channel. Science $257,1694-1698$. doi: 10.1126/science. 1529355

Sun, L., Xiong, Y., Zeng, X., Wu, Y., Pan, N., Lingle, C. J., et al. (2009). Differential regulation of action potentials by inactivating and noninactivating $\mathrm{BK}$ channels in rat adrenal chromaffin cells. Biophys. J. 97, 1832-1842. doi: 10.1016/j.bpj. 2009.06.042

Tao, J., Shi, J., Liu, Z. R., and Ji, Y. H. (2012). Martentoxin: a unique ligand of BK channels. Sheng Li Xue Bao 64, 355-364.

Tian, L., Duncan, R. R., Hammond, M. S., Coghill, L. S., Wen, H., Rusinova, R., et al. (2001). Alternative splicing switches potassium channel sensitivity to protein phosphorylation. J. Biol. Chem. 276, 7717-7720. doi: 10.1074/jbc.C000741200

Uebele, V. N., Lagrutta, A., Wade, T., Figueroa, D. J., Liu, Y., McKenna, E., et al. (2000). Cloning and functional expression of two families of beta-subunits of the large conductance calcium-activated K+ channel. J. Biol. Chem. 275, 23211-23218. doi: 10.1074/jbc.M910187199

Valverde, M. A., Rojas, P., Amigo, J., Cosmelli, D., Orio, P., Bahamonde, M. I., et al. (1999). Acute activation of Maxi-K channels (hSlo) by estradiol binding to the beta subunit. Science 285, 1929-1931. doi: 10.1126/science.285.5435.1929

Wallner, M., Meera, P., and Toro, L. (1999). Molecular basis of fast inactivation in voltage and $\mathrm{Ca} 2+$-activated $\mathrm{K}+$ channels: a transmembrane beta-subunit homolog. Proc. Natl. Acad. Sci. U.S.A. 96, 4137-4142. doi: 10.1073/pnas.96.7.4137

Wang, B., and Brenner, R. (2006). An S6 mutation in BK channels reveals betal subunit effects on intrinsic and voltage-dependent gating. J. Gen. Physiol. 128, 731-744. doi: 10.1085/jgp.200609596

Wang, B., Rothberg, B. S., and Brenner, R. (2006). Mechanism of B4 Subunit Modulation of BK Channels. J. Gen. Physiol. 127, 449-465. doi: 10.1085/jgp.200509436

Wang, B., Rothberg, B. S., and Brenner, R. (2009). Mechanism of increased BK channel activation from a channel mutation that causes epilepsy. J. Gen. Physiol. 133, 283-294. doi: 10.1085/jgp.200810141

Wang, G., Thorn, P., and Lemos, J. R. (1992). A novel large-conductance Ca(2+)activated potassium channel and current in nerve terminals of the rat neurohypophysis. J. Physiol. 457, 47-74.

Wang, Y. W., Ding, J. P., Xia, X. M., and Lingle, C. J. (2002). Consequences of the stoichiometry of Slo1 alpha and auxiliary beta subunits on functional properties of large-conductance Ca2+-activated K+ channels. J. Neurosci. 22, 1550-1561.

Wanner, S. G., Koch, R. O., Koschak, A., Trieb, M., Garcia, M. L., Kaczorowski, G. J., et al. (1999). High-conductance calcium-activated potassium channels in rat brain: pharmacology, distribution, and subunit composition. Biochemistry 38, 5392-5400. doi: 10.1021/bi983040c

Weiger, T. M., Holmqvist, M. H., Levitan, I. B., Clark, F. T., Sprague, S., Huang, W. J., et al. (2000). A novel nervous system beta subunit that downregulates human large conductance calcium-dependent potassium channels. J. Neurosci. 20, 3563-3570.

White, R. E., Han, G., Maunz, M., Dimitropoulou, C., El-Mowafy, A. M., Barlow, R. S., et al. (2002). Endothelium-independent effect of estrogen on $\mathrm{Ca}(2+)$ activated $\mathrm{K}(+)$ channels in human coronary artery smooth muscle cells. Cardiovasc. Res. 53, 650-661. doi: 10.1016/S0008-6363(01)00428-X

Wijetunge, L. S., Chattarji, S., Wyllie, D. J., and Kind, P. C. (2013). Fragile X syndrome: from targets to treatments. Neuropharmacology 68, 83-96. doi: 10.1016/j.neuropharm.2012.11.028

Xia, X. M., Ding, J. P., and Lingle, C. J. (1999). Molecular basis for the inactivation of $\mathrm{Ca} 2+-$ and voltage-dependent BK channels in adrenal chromaffin cells and rat insulinoma tumor cells. J. Neurosci. 19, 5255-5264.

Xia, X. M., Zeng, X., and Lingle, C. J. (2002). Multiple regulatory sites in largeconductance calcium-activated potassium channels. Nature 418, 880-884. doi: 10.1038 /nature00956

Xie, J., and McCobb, D. P. (1998). Control of alternative splicing of potassium channels by stress hormones. Science 280, 443-446. doi: 10.1126/science.280.5362.443

Zhang, X., Solaro, C. R., and Lingle, C. J. (2001). Allosteric regulation of BK channel gating by $\mathrm{Ca}(2+)$ and $\mathrm{Mg}(2+)$ through a nonselective, low affinity divalent cation site. J. Gen. Physiol. 118, 607-636. doi: 10.1085/jgp.118.5.607

Conflict of Interest Statement: The authors declare that the research was conducted in the absence of any commercial or financial relationships that could be construed as a potential conflict of interest.

Received: 17 July 2014; accepted: 15 September 2014; published online: 09 October 2014.

Citation: Wang B, Jaffe DB and Brenner $R$ (2014) Current understanding of iberiotoxin-resistant BK channels in the nervous system. Front. Physiol. 5:382. doi: 10.3389/fphys.2014.00382

This article was submitted to Membrane Physiology and Membrane Biophysics, a section of the journal Frontiers in Physiology.

Copyright (C) 2014 Wang, Jaffe and Brenner. This is an open-access article distributed under the terms of the Creative Commons Attribution License (CC BY). The use, distribution or reproduction in other forums is permitted, provided the original author(s) or licensor are credited and that the original publication in this journal is cited, in accordance with accepted academic practice. No use, distribution or reproduction is permitted which does not comply with these terms. 